\title{
The Enhanced Liver Fibrosis test is associated with liver-related outcomes in postmenopausal women with risk factors for liver disease
}

Paul M. Trembling ${ }^{1 *}$, Sophia Apostolidou ${ }^{2}$, Aleksandra Gentry-Maharaj ${ }^{2}$, Julie Parkes ${ }^{3}$, Andy Ryan², Sudeep Tanwar ${ }^{1}$, Matthew Burnell ${ }^{2}$, Scott Harris ${ }^{3}$, Usha Menon ${ }^{2 \dagger}$ and William M. Rosenberg ${ }^{1 \dagger}$

\begin{abstract}
Background: Chronic liver disease (CLD) is usually asymptomatic but earlier detection is critical to permit lifesaving interventions for those at risk due to high alcohol consumption and increased body mass index (BMI). The aim of this study was to estimate the association between the Enhanced Liver Fibrosis (ELF) test and liver-related events (LRE) and its performance in predicting LRE in postmenopausal women with risk factors in a nested case-control study within the United Kingdom Trial of Ovarian Cancer Screening (UKCTOCS).

Methods: In a cohort of 95,126 we performed a case-control study measuring ELF in blinded samples from 173 participants with self-reported high alcohol use and / or BMI $\geq 25 \mathrm{~kg} / \mathrm{m}^{2}$ comprising all 58 cases who developed LRE and 115 controls matched for age, alcohol and BMI who did not develop LRE during median follow-up of 8.5 years.

Results: Using Cox regression at an ELF threshold of 10.51 hazard ratios (HR) for LRE were 4.88 (95\% confidence interval (Cl) 2.37-10.03) (unadjusted model) and 4.62 (95\% Cl 2.12-10.08) (adjusted for deprivation and self-reported hypertension, heart disease, hypercholesterolaemia and diabetes). At a threshold of $9.8 \mathrm{HR}$ for LRE were 2.21 (95\% Cl 1.22-3.97) (unadjusted model) and 2.18 (95\% Cl 1.19-4.01) (adjusted). ELF was evaluated as a time dependent variable by generating time-dependent Cox models; HRs at an ELF threshold of 10.51 were 1.94 (95\% Cl 1.10-3.39) (unadjusted) and 2.05 (95\% Cl 1.16-3.64) (adjusted) and at a threshold of $9.8 \mathrm{HRs}$ were 1.85 (95\% Cl 1.09-3.15) (unadjusted) and 1.80 (95\% Cl 1.04-3.13) (adjusted). Area under the receiver operating characteristic curve for recruitment ELF predicting LRE was 0.58 ( $95 \% \mathrm{Cl} 0.49-0.68$ ), and for second subsequent ELF 0.61 (95\% Cl 0.52-0.71).

Conclusion: This study demonstrates the association between ELF and CLD in postmenopausal women with risk factors for liver disease, creating the opportunity to intervene to reduce liver-related mortality and morbidity. Although larger studies are required, these results demonstrate the potential of ELF as a prognostic tool in health checks in primary care.

(Continued on next page)
\end{abstract}

\footnotetext{
* Correspondence: p.trembling@ucl.ac.uk

†Usha Menon and William M Rosenberg are Joint senior authors.

'Division of Medicine, University College London, Institute for Liver and

Digestive Health, Royal Free Hospital, Rowland Hill Street, London NW3 2PF,

UK

Full list of author information is available at the end of the article
}

(c) The Author(s). 2020 Open Access This article is licensed under a Creative Commons Attribution 4.0 International License, which permits use, sharing, adaptation, distribution and reproduction in any medium or format, as long as you give appropriate credit to the original author(s) and the source, provide a link to the Creative Commons licence, and indicate if changes were made. The images or other third party material in this article are included in the article's Creative Commons licence, unless indicated otherwise in a credit line to the material. If material is not included in the article's Creative Commons licence and your intended use is not permitted by statutory regulation or exceeds the permitted use, you will need to obtain permission directly from the copyright holder. To view a copy of this licence, visit http://creativecommons.org/licenses/by/4.0/ The Creative Commons Public Domain Dedication waiver (http://creativecommons.org/publicdomain/zero/1.0/) applies to the data made available in this article, unless otherwise stated in a credit line to the data. 
(Continued from previous page)

Trial registration: This study is nested in UKCTOCS. UKCTOCS is registered as an International Standard Randomised Controlled Trial, number ISRCTN22488978. Registered 06/04/2000.

Keywords: Alcohol-related liver disease, Non-alcoholic fatty liver disease, Obesity, Liver fibrosis

\section{Background}

Due to the rising prevalence of chronic liver disease (CLD), in particular driven by non-alcoholic fatty liver disease (NAFLD) and obesity, there is much potential in targeted case-finding strategies in the community in an attempt to identify liver disease. General practitioners should be aware of this group of patients, which is challenging due to lack of symptoms and signs, but need to be given tools to identify liver fibrosis and diagnostic tests for earlier identification of liver disease.

Although hazardous alcohol use is declining in the younger age groups, this is not the case in the over fifties [1]. Particularly worrying is the increasing proportion of women drinking in later life, driven by life events including bereavement, changes in personal circumstances and retirement [2]. Therefore, not only is it important for screening and treatment of alcohol misuse in the community, it is crucial to focus on the older population.

The Enhanced Liver Fibrosis (ELF) test is a noninvasive measure of liver fibrosis that requires a simple blood sample. The ELF test score, indicating the degree of fibrosis, is calculated from measurement of three markers of fibrosis; hyaluronic acid (HA), tissue inhibitor of matrix metalloproteinase-1 (TIMP-1) and aminoterminal propeptide of procollagen type III (PIIINP). The algorithm was initially derived from a cohort of individuals with CLD with a range of aetiologies [3].

In subsequent validation studies, the ELF test has been shown to identify liver fibrosis in patients with NAFLD, primary biliary cholangitis, primary sclerosing cholangitis, chronic hepatitis B and chronic hepatitis C [4-8] and to predict liver-related clinical outcomes [9].

We have previously described the association between increasing body mass index (BMI) and liverrelated events (LRE) in a large cohort of women participating in the United Kingdom Trial of Ovarian Cancer Screening (UKCTOCS) [10]. In the present study we aimed to investigate the association of the ELF test with LRE in postmenopausal women with risk factors comprising high BMI and / or high alcohol consumption in a case-control study using the PRoBE design (prospective-specimen-collection, retrospective-blinded-evaluation) [11].

\section{Methods}

\section{Study population}

This population was drawn from primary care records. In the UK the population are encouraged to register with a primary care physician or general practitioner who then holds their "primary (healthcare) care record." UKCTOCS is a multi-centre UK-based randomised controlled trial investigating the impact of ovarian cancer screening on mortality. Participants were identified at random from primary care and invited to register for the study. Between April 2001 and October 2005, 202,638 postmenopausal women aged 50-74 were recruited in England, Wales and Northern Ireland. Further information on the UKCTOCS study can be found elsewhere [12-15]. The study was nested in UKCTOCS.

\section{Exposures}

We calculated the BMI of each participant using selfreported height and weight $\left(\mathrm{BMI}\left(\mathrm{kg} / \mathrm{m}^{2}\right)=\right.$ weight $(\mathrm{kg}) /$ $\left(\right.$ height $\left.\left.^{2}\right)(\mathrm{m})\right)$, and then categorised BMI according to the World Health Organization's definitions; normal (< $\left.25 \mathrm{~kg} / \mathrm{m}^{2}\right)$, overweight $\left(25-<30 \mathrm{~kg} / \mathrm{m}^{2}\right)$ or obese $(\geq 30 \mathrm{~kg} /$ $\mathrm{m}^{2}$ ). Taking a pragmatic approach, we excluded participants from this study if self-reported height was less than $140 \mathrm{~cm}$ or greater than $210 \mathrm{~cm}$, and / or if selfreported weight lay outside the range $25-200 \mathrm{~kg}$. In addition, we excluded participants in whom calculated BMI lay outside the range $16-65 \mathrm{~kg} / \mathrm{m}^{2}$.

At approximately 3 years after entry to the study participants were asked to report their average current alcohol consumption over a typical week. We converted each response to UK alcohol units on the assumption that that one drink (one measure of spirit, half a pint of cider / beer or one glass of wine) comprised one unit (10 $\mathrm{ml}$ or $8 \mathrm{~g}$ of pure alcohol) [16]. Responses were categorised as follows; none, less than $1,1-3,4-6,7-10$, $11-15,16-20$ or $\geq 21$ units. The UK Chief Medical Officer's (CMO) guidance is to limit weekly alcohol intake to no more than 14 units per week (for men and women) [16]. This threshold falls within the 11-15 units / week category in the UKCTOCS categories, therefore in this study, this category was included in the definition of 'high alcohol'. Although this may over-estimate 'high alcohol' use it ensures women consuming alcohol over the recommended limit are included. We did not include 
participants in this study who failed to provide information on alcohol use.

\section{Covariates}

Participants in UKCTOCS completed a questionnaire which collected data on heart disease, hypercholesterolaemia, diabetes, hypertension and smoking status. Socioeconomic status was estimated using the Index of Multiple Deprivation 2007 (IMD) [17, 18]. IMD is a measure of deprivation based on the participants' postal codes. The score is the UK government's official measure of multiple deprivation and combines a number of indices including income, employment, health, education and crime.

\section{Follow up}

Cancer registrations and deaths in the UKCTOCS population were notified via a 'flagging' study with NHS Digital. Hospital inpatient and outpatient episode data were available through linkage of participants to the Hospital Episodes Statistics (HES) database. Each HES record reports a main diagnosis and up to 19 (inpatient admissions) and 11 (outpatient appointments) further diagnoses. Each death record reports the primary cause of death and additional contributory causes recorded on the death certificate. Diagnoses and causes of death were coded in accordance with the International Classification of Diseases, version 10 (ICD-10). Participants in this nested study were followed up until 1 February 2013. Only participants in England were included, due to the availability of their relevant HES data. In an attempt to exclude participants with known liver disease, participants were excluded from the study if a code within our definition of liver disease was assigned to participants prior to the date of the follow-up questionnaire.

\section{Selection of cases and controls}

We performed a case-control study nested in UKCTOCS. Cases comprised all participants in the cohort with risk factors, defined as BMI $\geq 25 \mathrm{~kg} / \mathrm{m}^{2}$ and / or self-reported alcohol consumption of $\geq 11$ drinks per week, with a first presentation of an LRE, defined as first presentation of one or more of the following: a hospital admission, outpatient appointment, cancer registration with, or death from, an ICD-10 code of interest. We searched for the following codes: K70 (alcoholic liver disease), K73 (chronic hepatitis) and K74 (fibrosis and cirrhosis). The use of these codes is consistent with other UK studies of cirrhosis $[19,20]$. We also searched for K76.0 (other diseases of the liver, including fat). Codes relating to sequelae of decompensated liver disease were also included; 185 (oesophageal varices), Z944 (liver transplant) and C22.0 (hepatocellular carcinoma). In addition to ICD-10 code, death certificates were also searched for any mention of alcoholic liver disease or fatty liver.
Each case was matched to two controls in order to reduce selection bias. Controls were participants with risk factors who did not experience an LRE. The control matching criteria were: age $(+/-5$ years $)$ at recruitment, BMI $\left(+/-2 \mathrm{~kg} / \mathrm{m}^{2}\right)$, alcohol group and regional trial (recruitment) centre. Cases were not matched for time to spin (the time between sample collection and centrifugation of sample) or storage time of sample.

\section{Sample collection and serum marker testing}

Stored serum samples were retrieved from the UKCTOCS cryorepository for testing. From cases, blood samples selected for his study were those taken at trial recruitment (sample 1) and at two further time points before LRE (samples 2 and 3). Samples taken up to 6 months prior to the event were not included to reduce risk of the liver event itself influencing the ELF score. In controls, blood samples selected were those taken at recruitment and two similar time points to the respective cases.

Samples were collected into Greiner Bio-One gel tubes (Greiner Bio-One Ltd., Stonehouse) at the UKCTOCS trial centres and shipped overnight at room temperature to the central laboratory. Samples were centrifuged at $1500 \mathrm{~g}$ for $10 \mathrm{~min}$ and the separated serum aliquoted into $10 \times 500 \mu \mathrm{l}$ straws using a semi-automated MAPI platform (MAPI CryoBioSystem, Cryo Bio System, Paris, France). The straws were heat-sealed, barcoded, databased and frozen using a two-stage process; $24 \mathrm{~h}$ at $80^{\circ} \mathrm{C}$ and then in liquid nitrogen (vapour phase at $180^{\circ} \mathrm{C}$ ) tanks at the central laboratory which, when full, were transported to a Human Tissue Authority licensed, International Organization for Standardization accredited commercial cryofacility (Fisher Bioservices, UK). The subset of samples selected for the current study were thawed and immediately aliquoted into 2D barcoded tubes for ELF testing.

The ELF test was performed at the Central ELF laboratory (iQur, London). Serum samples were analysed for levels of HA, TIMP-1 and PIIINP using the proprietary assays developed for the ELF test by Siemens Healthineers Inc. These assays are magnetic particle separation immunoassays, and samples were analysed on an ADVIA Centaur ${ }^{\odot}$ immunoassay system (Siemens Healthineers Inc., Tarrytown, NY, USA). Results were entered into the manufacturer's published algorithm to derive an ELF score.

\section{Statistical analysis}

We have previously evaluated potential confounding risk factors in univariate Cox proportional hazards models to determine their individual associations with liver disease, confirming that deprivation score and self-reported 
hypertension, heart disease, hypercholesterolaemia and diabetes were all independently associated with risk [10].

\section{Analysis of recruitment samples}

Cox proportional hazards models were generated to evaluate the association of ELF score at recruitment with LRE. Univariate models were produced, and then adjusted for covariates listed above for ELF score thresholds of 9.8, as recommended by the manufacturer in the ELF instructions for use (Siemens Healthineers) and 10.51, a threshold recommended in the National Institute for Health and Care Excellence (NICE) Guidance No.49 on management of NAFLD and used in the stratification of patients with alcohol related liver disease [21]. This threshold was selected by NICE based on the performance of the ELF test in predicting liver fibrosis stage using liver biopsy as the reference in a paediatric cohort of NAFLD [5].

\section{Analysis of serial samples}

To evaluate ELF as a time-dependent variable (and to minimise immortal time bias), time-dependent Cox analysis was performed using the same ELF thresholds [22]. Immortal time bias refers to the period of follow-up during which the study outcome could not have occurred. It occurs with the passing of time before a participant is subject to the exposure or defined level of the covariate (e.g. ELF $\geq 9.8$ ). The period is considered immortal because participants necessarily had to remain event-free until the time of 'exposure' (in this case a high ELF score) to be classified as 'exposed'. An incorrect consideration of this 'unexposed' time period will lead to immortal time bias $[23,24]$. In this study, the time during follow-up at which ELF reached the threshold was assumed to be the time of the first sample in which ELF was measured at or above that threshold. Both univariate and adjusted models were produced.

\section{Exploration of ELF thresholds}

Performance of the ELF test was further evaluated by deriving the area under the receiver operator characteristic (AUROC) curves (with 95\% confidence intervals (CI)). Optimal cut-off values for discriminating between cases and controls were determined by identifying the ELF score at the point of maximum sensitivity and specificity on the ROC curve, by calculating the Youden Index. Diagnostic odds ratios of these single threshold models were calculated.

The potential clinical utility of the ELF test in this population was further evaluated by selecting an upper ELF threshold with high specificity, therefore high positive predictive value to 'rule in' an event and a low threshold with high sensitivity and therefore high negative predictive value to 'rule out' an event, at a range of sensitivities and specificities. The proportion of subjects in which a second test would be needed to identify LRE was calculated for each model.

\section{Results}

Of the 95,126 participants from UKCTOCS studied (see Trembling et al., 2018 for details of this cohort) [10], 325 participants experienced a first LRE, of which 58 had recorded risk factors and at least three serial serum samples stored. These cases were matched to 116 controls as described above. Of the 522 samples selected, one control (3 samples) was excluded as per UKCTOCS protocol due to a diagnosis of ovarian cancer during follow-up, and one subsequent sample from a case was not available. Derivation of the study population is shown in Fig. 1.

\section{Baseline characteristics}

Baseline characteristics of the study cohort are presented in Table 1. Median recruitment age was 61 years (range $52-74)$. High alcohol use was reported by $19 \%$ and BMI $\geq 25 \mathrm{~kg} / \mathrm{m}^{2}$ in $88 \%$. Median time to LRE / censor was 8.5 years (range $0.5-11.4$ ).

As per the matching strategy, there was no significant difference in age and there were no significant differences in the proportions of each BMI group and of each alcohol group between the cases and control groups.

The most prevalent comorbidity was hypertension (37\%), followed by hypercholesterolaemia (31\%), heart disease (12\%), type 2 diabetes (3\%) and stroke (0.6\%). There were significantly more self-reported diagnoses of type 2 diabetes in the cases compared to controls, but there was no significant difference in prevalence of hypertension, heart disease or stroke between groups. There was a significantly higher mean deprivation score in the cases.

\section{Outcomes}

Median interval from recruitment sample to a first presentation of a LRE in cases was 3.8 years (interquartile range 1.5). In controls, median follow-up with no event was 9.8 years (interquartile range 2.1 ).

The most common ICD-10 code for the study definition of LRE was K76, 'other diseases of the liver'. When cases with LREs coding for complications of liver disease (I85, Z944 and / or C22.0) were compared to cases with any other LRE code, mean recruitment ELF score, first subsequent ELF score and second subsequent ELF score were not significantly different $(9.409$ v 9.350, $p=0.890$; 9.540 v 9.966, $p=0.341 ; 9.646$ v $10.161, p=0.204$, respectively). The LREs for the cases are shown in Additional file: Table S1. 


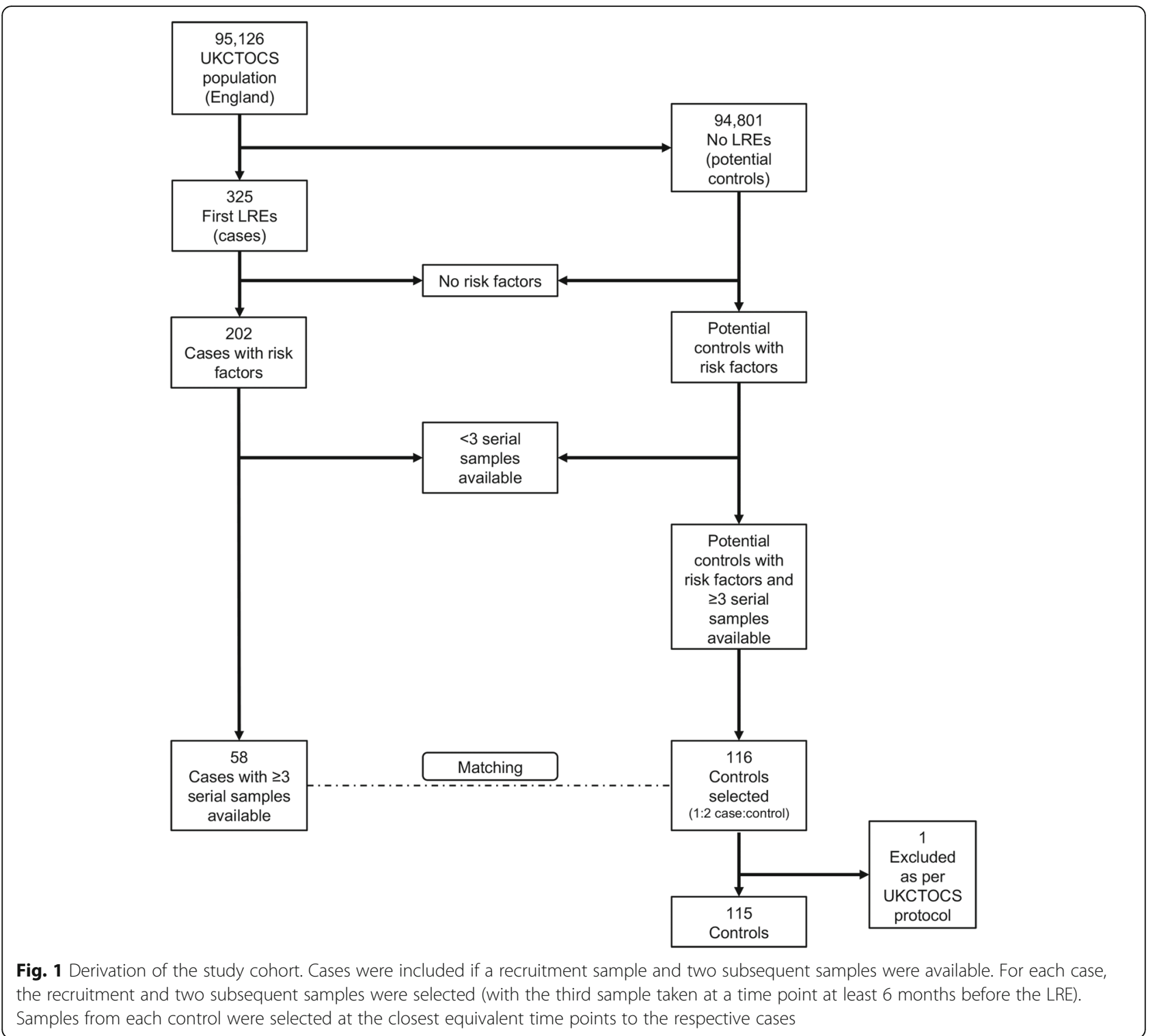

\section{ELF scores}

Mean ELF scores for recruitment, subsequent samples and combined subsequent samples are shown in Table 2 and median values for recruitment and the second subsequent samples in Fig. 2. The mean concentrations for the three components of the ELF assay for cases and controls are shown in Additional file: Table S2. The mean ELF score in the recruitment samples was higher in the cases compared to the controls (9.36 and 8.96, respectively).

Fifteen (25.9\%) cases had a recruitment ELF score of $\geq 9.8$ compared with 14 (12.2\%) controls. Nine (15.5\%) cases had a recruitment ELF score of $\geq 10.51$ compared to $2(1.7 \%)$ controls.

When the time to first LRE in the cases was divided at the median, the mean recruitment ELF score was higher in the group with a shorter time to event compared to the group with the longer time to event (9.45 (standard deviation 1.34) and 9.26 (standard deviation 0.91), respectively $(p=0.15))$.

HR estimates for ELF at recruitment are shown in Table 3. With an ELF threshold of 9.8 to identify advanced fibrosis or cirrhosis (Metavir histological stage F3/F4) [25], HR for LRE was 2.21 in the unadjusted model and 2.18 in the adjusted model. At the threshold of 10.51, HR in the unadjusted model was 4.88 and in the adjusted model HR was 4.62. Cumulative hazard estimates for both models are shown in Figs. 3 and 4 .

In the time-dependent Cox models, at an ELF threshold of 9.8 HRs are 1.85 and 1.80 in the unadjusted and adjusted models, respectively, and at a threshold of 10.51, 
Table 1 Baseline characteristics of study participants and comparisons between cases and controls. Data are presented for the study cohort, categorised in to cases and controls, for mean deprivation score, numbers of self-reported comorbidities, and WHO BMI categories. Tests of statistical differences were applied

\begin{tabular}{|c|c|c|c|c|c|}
\hline \multicolumn{2}{|l|}{ Characteristic } & Cases & Controls & All participants & $\boldsymbol{p}$ value $^{\dagger}$ \\
\hline \multicolumn{2}{|l|}{ Participants, $n$} & 58 & $115^{\ddagger}$ & 173 & \\
\hline \multicolumn{2}{|c|}{ Age at recruitment, median (range) } & $60.9(51.6-74.3)$ & $61.5(51.8-74.2)$ & $61.0(51.8-74.3)$ & $0.8501^{\mathrm{a}, \mathrm{d}}$ \\
\hline \multicolumn{2}{|c|}{ IMD, mean (SD) } & $25.55(17.03)$ & $19.86(15.61)$ & $21.8(16.3)$ & $0.031^{\mathrm{a}}$ \\
\hline \multicolumn{2}{|c|}{ Hypertension, $n(\%)$} & $26(44.8)$ & $39(33.9)$ & $65(37.6)$ & $0.162^{b}$ \\
\hline \multicolumn{2}{|c|}{ Heart disease, $n(\%)$} & $8(13.8)$ & $13(11.3)$ & $21(12.1)$ & $0.636^{\mathrm{b}}$ \\
\hline \multicolumn{2}{|c|}{ Hypercholesterolaemia, n (\%) } & $22(37.9)$ & $32(27.8)$ & $54(31.2)$ & $0.176^{b}$ \\
\hline \multicolumn{2}{|c|}{ Type 2 diabetes, $n(\%)$} & $11(19.0)$ & $5(4.3)$ & $16(3.4)$ & $0.002^{b}$ \\
\hline \multicolumn{2}{|c|}{ Smoker, $n(\%)^{\mathrm{e}}$} & $33(57)$ & 38 (33) 13 missing & 71 (44.4) 13 missing & $0.016^{b}$ \\
\hline \multicolumn{2}{|l|}{ Stroke, $n(\%)$} & $1(1.7)$ & $0(0.0)$ & $1(0.6)$ & $0.335^{c}$ \\
\hline \multirow{3}{*}{$\begin{array}{l}\mathrm{BMl} \\
\left(\mathrm{kg} / \mathrm{m}^{2}\right) \\
n,(\%)\end{array}$} & $<25$ & $7(12.1)$ & $15(13.0)$ & $22(12.7)$ & $0.856^{\mathrm{a}, \mathrm{d}}$ \\
\hline & $25-<30$ & $33(56.9)$ & $65(56.5)$ & $98(56.6)$ & $0.963^{\mathrm{a}, \mathrm{d}}$ \\
\hline & $\geq 30$ & $18(31.0)$ & $35(30.4)$ & $53(30.6)$ & $0.936^{\mathrm{a}, \mathrm{d}}$ \\
\hline \multirow{5}{*}{$\begin{array}{l}\text { Alcohol } \\
\text { (units/week) } \\
n,(\%)\end{array}$} & None & $18(31.0)$ & 35 (30.4) & 53 (30.6) & $0.936^{\mathrm{a}, \mathrm{d}}$ \\
\hline & $<1-10$ & $29(50.0)$ & $58(50.4)$ & 87 (50.3) & $0.957^{\mathrm{a}, \mathrm{d}}$ \\
\hline & $11-15$ & $7(12.1)$ & $14(12.2)$ & $21(12.1)$ & $0.984^{\mathrm{a}, \mathrm{d}}$ \\
\hline & $16-20$ & $2(3.4)$ & $4(3.5)$ & $6(3.5)$ & $0.992^{\mathrm{a}, \mathrm{d}}$ \\
\hline & $\geq 21$ & $2(3.4)$ & $4(3.5)$ & $6(3.5)$ & $0.992^{\mathrm{a}, \mathrm{d}}$ \\
\hline
\end{tabular}

WHO World Health Organization, $B M I$ body mass index, IMD Index of Multiple Deprivation

${ }^{\dagger}$ at the $5 \%$ level. ${ }^{\ddagger}$ One control excluded as per UKCTOCS protocol

${ }^{a}$ Independent sample t-test; ${ }^{b}$ Pearson's Chi-square test; ${ }^{c}$ Fisher's exact test; ${ }^{d}$ Matched variable; ${ }^{e}$ variable excluded from regression analyses

Table 2 Mean ELF scores for cases and controls in recruitment samples, subsequent samples and in the combined subsequent samples. Numbers of participants in each group are shown with corresponding mean ELF test score, for first sample (recruitment samples), subsequent sample 1 (second samples) and subsequent sample 2 (third samples)

\begin{tabular}{|c|c|c|c|}
\hline \multirow[t]{2}{*}{ Sample type } & \multicolumn{2}{|l|}{ Case / control } & \multirow[t]{2}{*}{$\boldsymbol{p}$ value $^{\dagger}$} \\
\hline & Cases $^{a}$ & Controls $^{\mathrm{b}}$ & \\
\hline \multicolumn{4}{|l|}{ Recruitment sample } \\
\hline Number of participants & 58 & 115 & 0.007 \\
\hline Mean ELF score (SD) & $9.355(1.136)$ & $8.959(0.743)$ & \\
\hline \multicolumn{4}{|l|}{ Subsequent sample 1} \\
\hline Number of participants & 58 & 115 & 0.030 \\
\hline Mean ELF score (SD) & $9.901(1.198)$ & $9.588(0.798)$ & \\
\hline \multicolumn{4}{|l|}{ Subsequent sample 2} \\
\hline Number of participants & 57 & 115 & 0.002 \\
\hline Mean ELF score (SD) & $10.143(1.017)$ & $9.669(0.807)$ & \\
\hline \multicolumn{4}{|c|}{ Combined subsequent samples } \\
\hline Number of participants & 115 & 230 & $<0.001$ \\
\hline Mean ELF score (SD) & $10.022(1.138)$ & $9.628(0.802)$ & \\
\hline
\end{tabular}

ELF enhanced liver fibrosis, SD standard deviation ${ }^{\dagger}$ at the $5 \%$ level

a One subsequent sample not available for testing

${ }^{\mathrm{b}}$ One control excluded from analysis as per UKCTOCS protocol due to a diagnosis of ovarian cancer
HRs are 1.94 and 2.05 in the unadjusted and adjusted models, respectively.

\section{Exploration of ELF thresholds and clinical utility models}

The AUROC for recruitment ELF predicting event was 0.583 (95\% CI 0.487-0.678), and for second subsequent ELF 0.613 (95\% CI 0.521-0.705).

The Youden Index for recruitment ELF was 0.214, with an optimal calculated ELF threshold of 9.535 (sensitivity $37.9 \%$, specificity $83.5 \%$ ). The Youden Index for second subsequent ELF was 0.228, with an optimal calculated ELF threshold of 10.325 (sensitivity 39.3\%, specificity 83.5\%). In these 'fully assigned' models, the diagnostic accuracy using recruitment ELF would be $68.2 \%$, and using the second subsequent ELF score $69 \%$. The diagnostic odds ratios for each model are 3.1 and 3.3, respectively.

The calculated dual thresholds at a range of sensitivities and specificities are shown in Table 4, along with diagnostic accuracy, misclassification and indeterminate rates. In these models, compared to single threshold models, the misclassification rates are lower, but at the expense of diagnostic accuracy and need for a second test to classify indeterminate subjects.

\section{Discussion}

This prospective case-control study demonstrates the association of the ELF test score with liver-related 
a)

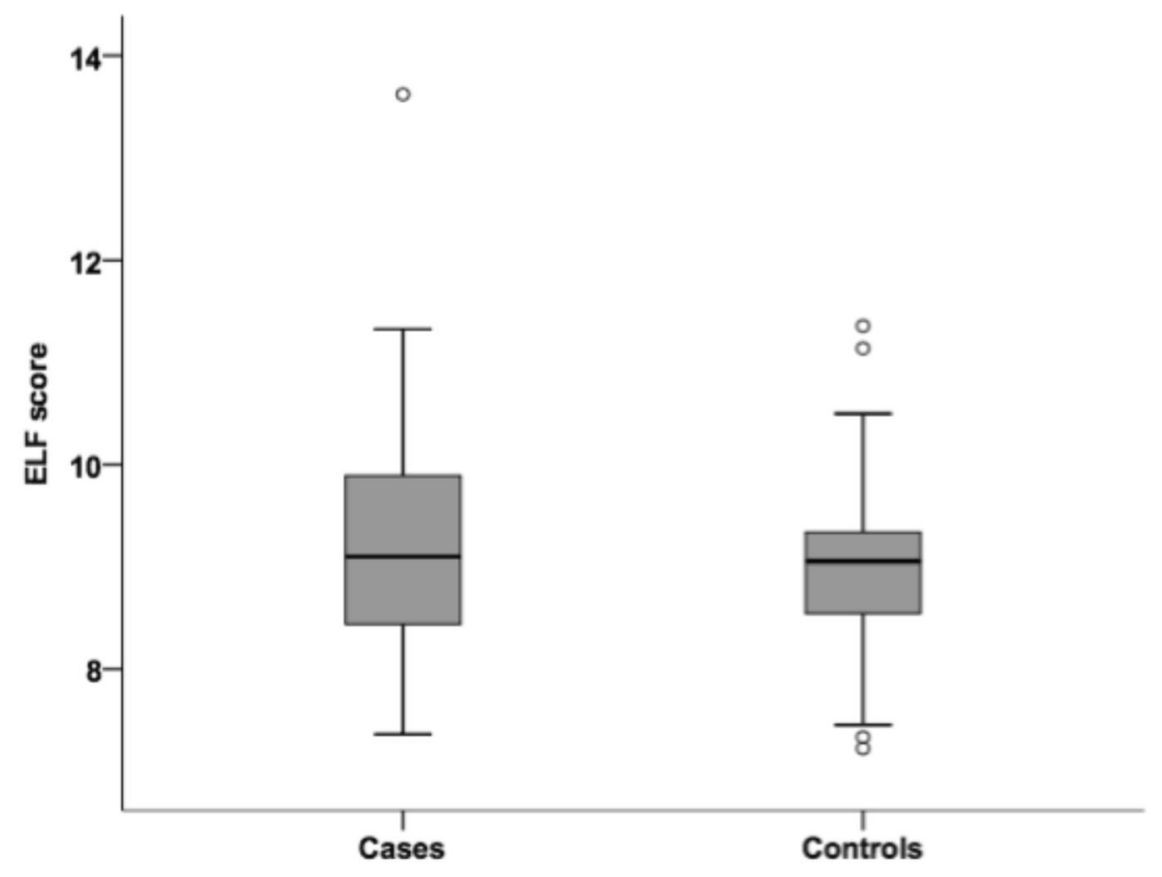

b)

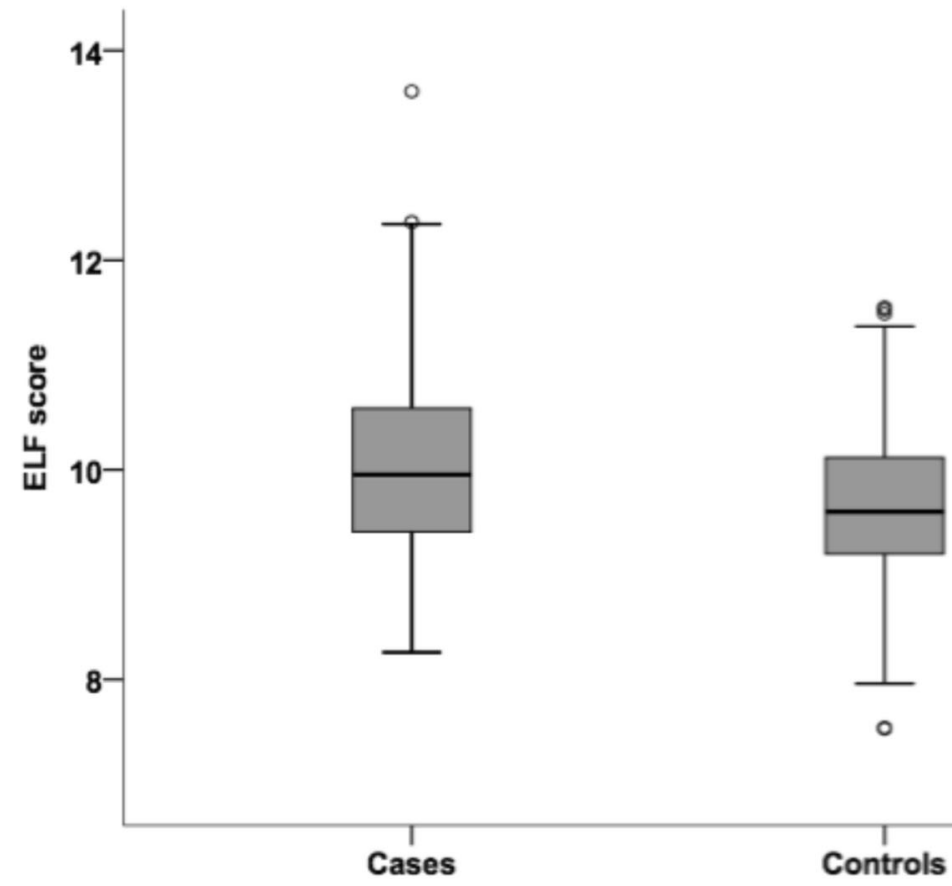

Fig. 2 Box plots for ELF scores in a cases and $\mathbf{b}$ controls. Plots show median ELF scores, 25th and 75th percentiles, and minimum and maximum values (outliers are also shown) 
Table 3 Hazard ratio estimates for liver-related event at ELF thresholds of 9.8 and 10.51. Hazard ratio estimates are presented using standard Cox proportional hazards and using time-dependent Cox analysis for liver-related event, at two ELF thresholds. Hazard ratio estimates are shown in unadjusted models and in models adjusted for deprivation, hypertension, heart disease, hypercholesterolaemia and diabetes

\begin{tabular}{|c|c|c|c|c|c|}
\hline \multirow{2}{*}{$\begin{array}{l}\text { ELF } \\
\text { threshold }\end{array}$} & \multirow{2}{*}{$\begin{array}{l}\text { Unadjusted } \\
\text { / adjusted }\end{array}$} & \multicolumn{2}{|l|}{ Cox } & \multicolumn{2}{|l|}{ Time-dependent Cox } \\
\hline & & $\mathrm{HR}(95 \% \mathrm{Cl})$ & $\boldsymbol{p}$ value $^{\dagger}$ & $\mathrm{HR}(95 \% \mathrm{Cl})$ & $\boldsymbol{p}$ value $^{\dagger}$ \\
\hline \multirow[t]{2}{*}{9.8} & Unadjusted & $2.205(1.224-3.971)$ & 0.008 & $1.854(1.092-3.148)$ & 0.022 \\
\hline & Adjusted & $2.184(1.189-4.013)$ & 0.012 & $1.804(1.041-3.126)$ & 0.035 \\
\hline \multirow[t]{2}{*}{10.51} & Unadjusted & $4.880(2.374-10.029)$ & $<0.0001$ & $1.935(1.104-3.391)$ & 0.021 \\
\hline & Adjusted & $4.617(2.115-10.081)$ & $<0.0001$ & $2.053(1.157-3.644)$ & 0.014 \\
\hline
\end{tabular}

ELF enhanced liver fibrosis, $H R$ hazard ratio, $\mathrm{Cl}$ confidence interval

${ }^{\dagger}$ at the $5 \%$ level

outcomes in a general population of postmenopausal women with risk factors for liver disease in the form of high BMI, high alcohol consumption or both. ELF scores were higher in those participants who subsequently experienced a liver-related event earlier. Time to event analysis demonstrated an association between ELF and LRE, with a hazard ratio of 2 compared to women who do not experience LRE. To the best of our knowledge, this is the first study to evaluate the performance of the ELF test to predict a range of LREs in a general population.

The clinical utility models indicate that the ELF test may have a role in diagnosing liver disease in this low prevalence population, using a single threshold. The AUROC in our study was not highly predictive, and further population studies are required.

\section{Strengths and limitations}

Strengths of this population-based study include the prospective design and the independence of data capture for outcomes. This study used ICD-10 codes for CLD that have been used in other studies of cirrhosis, however in an attempt to maximise identification of liver disease we also included codes relating to clinical consequences of advanced cirrhosis. Evaluation of numerous possible confounders including self-reported comorbidities and socioeconomic status minimised bias. Although the number of cases of liver related events was only 58 it is important to recognize that this was the total number of incident cases occurring in a cohort of 95,126 women sampled for this study and so the cases represent a comprehensive sample of participants developing LRE.

ELF tests were performed in one central laboratory, ensuring quality control and consistency, using the proprietary ELF assays. The stability of the ELF test, when applied to samples exposed to a range of common storage conditions, has been demonstrated [26].

Limitations of this study include the reliance of selfreporting of height and weight and co-morbidities. There is evidence, however, of good reliability of self- reporting height and weight from other studies [27-30], for example in a longitudinal study examining agreement between self-reported and measured height, weight and body mass index in older people [31]. Several studies have demonstrated good accuracy in recalled weight, with some data indicating underestimation in those with higher BMI [32-35].

As previously discussed, the UKCTOCS alcohol categories do not align with the CMO's threshold for hazardous drinking of 14 units / week and therefore including the UKCTOCS threshold of 11-15 units / week may have over-estimated 'high alcohol use'; however excluding this category in this study would have risked excluding some women with hazardous alcohol consumption.

It is possible that reliance on ICD-10 codes to define events may lead to errors due to mis-coding. We interrogated three independent sources in an attempt to reduce risk of non-coding. Further, HES data may not capture clinical events in a number of areas of healthcare, including the private sector. There is no clear definition for liver disease and consequently, due to large variation in data definitions, comparing incidence between studies is difficult. The problem facing clinicians is that nearly $50 \%$ of individuals with liver disease only receive the diagnosis when they present to hospital with a decompensating event [36]. In the community setting the focus must be on identifying liver disease not only at the point of a clinical event but before this where intervention may be more effective. By selecting a group of codes for our data definition, we are contributing to the heterogeneity of definitions in this area. Further work is required to find agreement amongst investigators.

Ninety seven percent of the UKCTOCS population was white. This ethnic homogeneity may have implications for general applicability of the data, in addition to the use of 'normal' ELF score ranges. Finally, an evaluation of the ELF test in a secondary care population in Australia reported a positive correlation with age, not seen in the original ELF studies [37]. More work may be required to determine 
a)

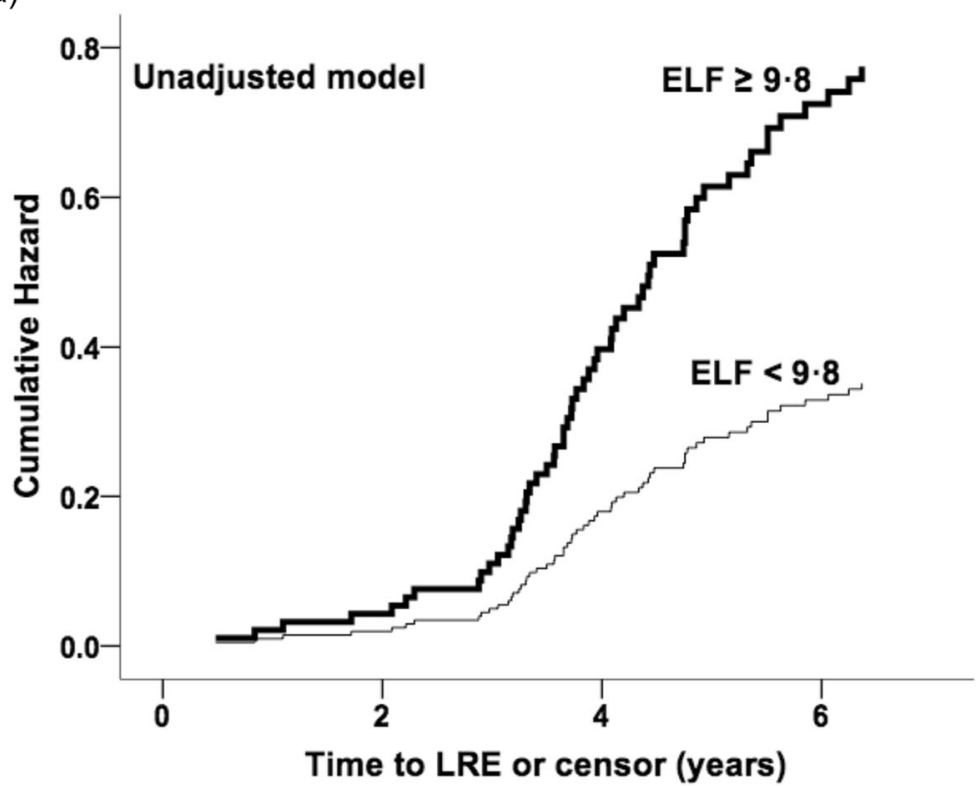

b)

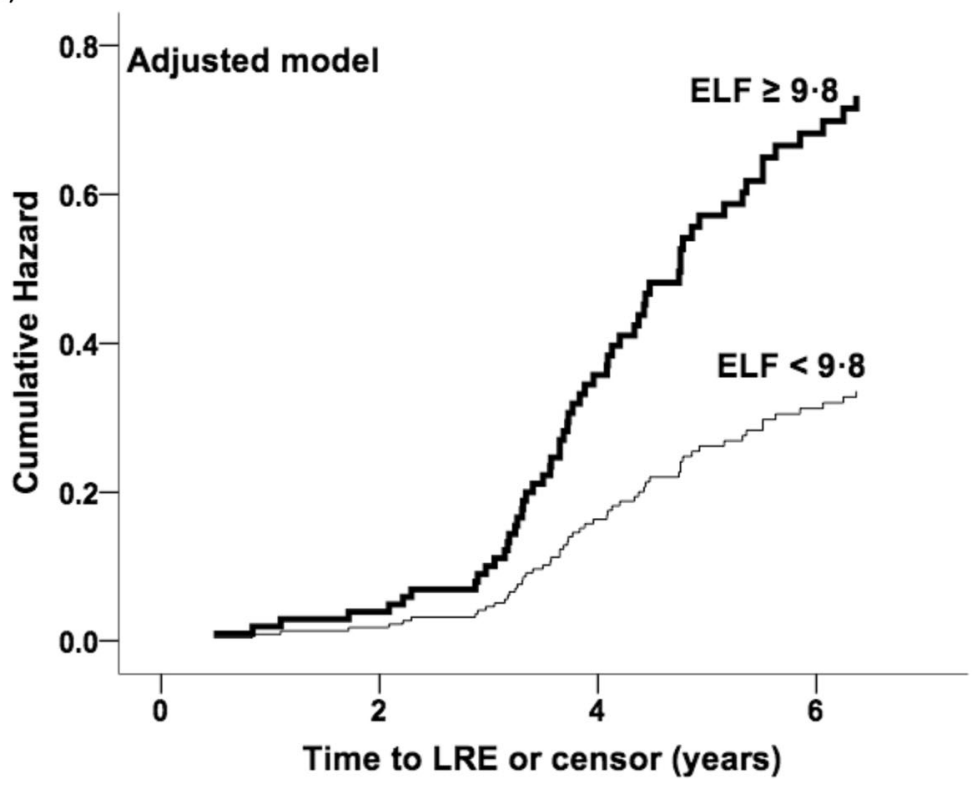

Fig. 3 Cumulative hazards for LRE using ELF threshold of 9.8. Cumulative hazards plots for liver-related event for ELF threshold of 9.8 are shown, for $\mathbf{a}$ an unadjusted model and $\mathbf{b}$ a model adjusted for deprivation, hypertension, heart disease, hypercholesterolaemia and diabetes

whether age-specific ranges are required in the general population.

\section{Other studies}

The incidence of CLD continues to rise [19, 38-40] and the asymptomatic nature of liver fibrosis progression, leading to cirrhosis results in individuals often presenting with life-threatening features of decompensation in the form of ascites, variceal haemorrhage, hepatic encephalopathy, liver failure or hepatocellular carcinoma [36]. Noninvasive evaluation of liver fibrosis is now established in clinical practice but remains largely confined to secondary and tertiary care settings where it is applied to patients with known or suspected liver disease. There is an urgent need to identify liver disease and the risk of progressive fibrosis in primary care, not least in those with risk factors, where the reliance on measurement of serum liver enzymes may be falsely reassuring [41-43]. 
a)

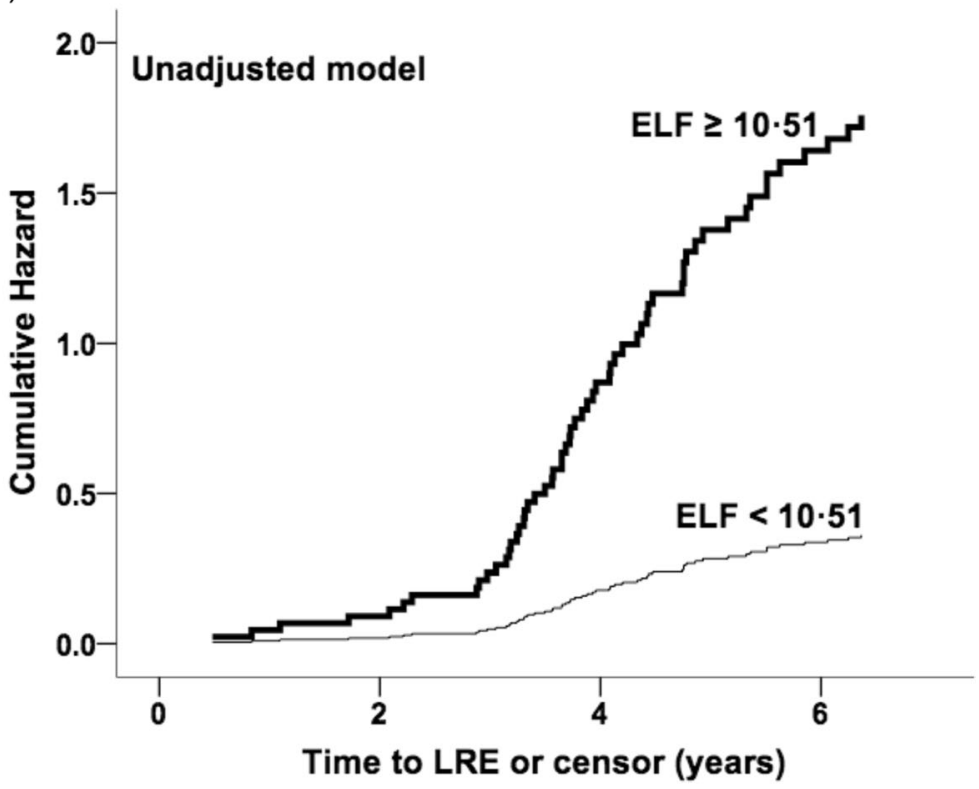

b)

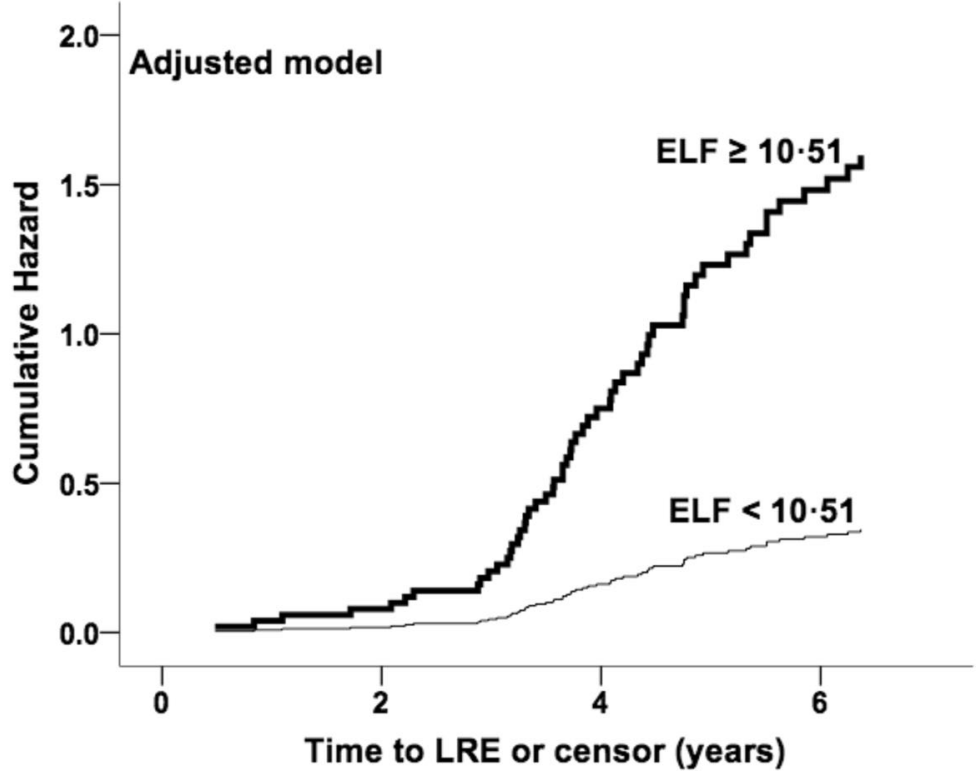

Fig. 4 Cumulative hazards for LRE using ELF threshold of 10.51. Cumulative hazards plots for liver-related event for ELF test threshold of 10.51 are shown, for $\mathbf{a}$ an unadjusted model and $\mathbf{b}$ a model adjusted for deprivation, hypertension, heart disease, hypercholesterolaemia and diabetes

Transient elastography (TE) has been the most extensively investigated and independently validated noninvasive test in the general population, with smaller numbers of studies evaluating and validating serumbased markers [44]. However, there is a lack of consensus on thresholds for levels of liver disease, both between tests and within the same test. This results in a wide variation in prevalence estimates. Furthermore, although elastography is a relatively rapid test which produces an instant result, automated blood tests, like the ELF test, can be included with other routine blood tests in primary care and, unlike $\mathrm{TE}$, require no training (which would be more difficult to provide in primary care) and have a lower failure rate compared to TE [45].

TE is operator dependent and although good interoperator variability in performance has been reported $[46,47]$, this is reduced at lesser stages of fibrosis and in 
Table 4 Diagnostic performance indices of ELF for identifying LRE using thresholds with sensitivity and specificity of 80,85 and $90 \%$. Data are presented showing ELF thresholds with sensitivity and specificity values of 80,85 and $90 \%$, with data-derived diagnostic accuracy (proportion of true positives and true negatives), misclassification rate (proportion of false negatives and false positives) and the rate of indeterminate cases (ELF score between the thresholds)

\begin{tabular}{|c|c|c|c|c|c|c|}
\hline $\begin{array}{l}\text { Sensitivity and specificity } \\
\text { values }\end{array}$ & $\begin{array}{l}\text { ELF } \\
\text { thresholds }\end{array}$ & $\begin{array}{l}\text { Sensitivity } \\
(\%)\end{array}$ & $\begin{array}{l}\text { Specificity } \\
(\%)\end{array}$ & $\begin{array}{l}\text { Diagnostic accuracy } \\
(\%)\end{array}$ & $\begin{array}{l}\text { Misclassification rate } \\
(\%)\end{array}$ & $\begin{array}{l}\text { Indeterminate } \\
(\%)\end{array}$ \\
\hline \multicolumn{7}{|l|}{ Recruitment samples } \\
\hline \multirow[t]{2}{*}{$80 \%$} & 8.350 & 81.0 & 19.1 & 26.0 & 19.7 & 54.3 \\
\hline & 9.425 & 39.7 & 80.0 & & & \\
\hline \multirow[t]{2}{*}{$85 \%$} & 8.270 & 84.5 & 16.5 & 26.0 & 19.7 & 54.3 \\
\hline & 9.750 & 27.6 & 85.2 & & & \\
\hline \multirow[t]{2}{*}{$90 \%$} & 8.160 & 91.4 & 14.8 & 26.0 & 19.7 & 54.3 \\
\hline & 9.895 & 24.1 & 90.4 & & & \\
\hline \multicolumn{7}{|l|}{ Second subsequent samples } \\
\hline \multirow[t]{2}{*}{$80 \%$} & 9.365 & 80.4 & 34.8 & 36.4 & 19.1 & 44.5 \\
\hline & 10.255 & 41.1 & 80.9 & & & \\
\hline \multirow[t]{2}{*}{$85 \%$} & 8.975 & 85.7 & 14.8 & 36.4 & 19.1 & 44.5 \\
\hline & 10.540 & 28.6 & 86.1 & & & \\
\hline \multirow[t]{2}{*}{$90 \%$} & 8.945 & 89.3 & 13.9 & 56.6 & 28.3 & 15.1 \\
\hline & 10.835 & 17.9 & 90.4 & & & \\
\hline
\end{tabular}

ELF enhanced liver fibrosis

individuals with hepatic steatosis, high BMI and in particular waist circumference. In its development of guidelines for management of NAFLD, NICE performed an extensive health economic comparison of non-invasive modalities, concluding that the ELF test was the most cost-effective test in this context [48]. More recently a prospective study in primary care has shown that the ELF test improved the detection of liver disease and in conjunction with the Fibrosis-4 (Fib-4) score, reduced inappropriate referrals of patients with NAFLD to secondary care [49]. The choice of modality utilised in a community-based setting is likely to be influenced by local expertise and experience and the prevailing capital and processing costs.

A recent meta-analysis collected data on TE values in healthy individuals identifying 26 studies and a total of 16,082 participants [50]. The mean liver stiffness in nonobese individuals was $4.68 \mathrm{kPa}$, with increased stiffness measurements in individuals with diabetes, increasing waist circumference, obesity, elevated serum transaminases or hypertension. Dedicated studies within primary care are, however, required.

A community-based study of participants with risk factors for liver disease comprising excess alcohol use, type 2 diabetes or elevated serum transaminases used simple serum marker algorithms with high negative predictive values to rule out significant liver fibrosis. Those with results indicating liver disease were invited to attend for TE. $12.1 \%$ had a normal initial test and of those with a valid elastography result, $27 \%$ had elevated liver stiffness [43].
A large study based in primary care examined the natural history of standard 'liver function tests' (LFT) measured in over 95,000 patients with no liver disease, followed up for a median of 3.7 years [41]. 1.14\% developed liver disease and at least one abnormality within the LFT panel was predictive of developing liver disease, for example the HRs for mild ALT and severe ALT rises were 4.23 and 12.67, respectively. Health economic analyses indicated that the most cost-effective strategy in those with abnormal LFTs with no obvious liver disease was to re-test in primary care and in those with high risk neither re-testing nor secondary care referral dominated. In a group of individuals from the general population participating in the National Health and Nutrition Examination Survey (NHANES) III survey, serum markers were applied to those with NAFLD and followed up for a median of 14.5 years. Increasing NAFLD fibrosis score, aspartate aminotransferase (AST) to platelet ratio (APRI) and Fib-4 scores were associated with increasing mortality, although the low number of liver related deaths was too small to analyse [51].

The ELF test has been evaluated in a group of obese patients undergoing bariatric surgery and who had suspected NAFLD with a significantly higher ELF score in those with non-alcoholic steatohepatitis (NASH) and / or fibrosis on biopsy compared to those with normal histology or steatosis [52]. Using histology as the reference standard, performance of the ELF test, FibroTest, elastography, and other simple serum marker panels (including APRI and Fib-4) were compared in a primary care cohort with a history of excess alcohol 
use. Using a cut off value of 10.5, the ELF test diagnosed advanced fibrosis with high accuracy (AUROC $=0.89$ ), with similar performance to FibroTest and elastography, but without test failures, and was more accurate than the simple marker panels [21].

The ELF test has been shown to predict clinical outcomes in mixed liver disease $[9,37]$, and in disease-specific populations, for example primary sclerosing cholangitis [53] and chronic hepatitis C [54]. A study in the general population evaluated the performance of the ELF test to predict development of hepatocellular carcinoma, demonstrating that an ELF score of $\geq 9.89$ had an odds ratio of 25 for predicting an event [55].

Several studies have defined the normal ELF score in healthy populations. In a South Korean cohort where heart disease, diabetes, metabolic syndrome, hepatitis B, hepatitis $C$ and liver dysfunction were excluded, the ELF test score in females was between 5.89 and 8.67 [56]. In a study using serum samples from 400 blood donors, the ELF test score in females was found to be between 6.6 and 9.3 [57]. In both studies, the average ELF score was higher in males. Our data adds to the understanding of normal ranges of ELF, showing a higher ELF score in a general population with risk factors, and higher still in those experiencing LRE.

\section{Conclusion}

This study builds on the growing body of evidence supporting the clinical utility of the ELF test in community settings for diagnosis of liver disease. We have demonstrated the association of the ELF test with clinically significant liver-related events in middleaged women with risk factors. Serum transaminases are inaccurate measures of CLD and the absence of symptoms or signs of early liver disease combined with the increasing rise in liver-related deaths highlight the need for accurate and reproducible tests to detect liver disease in people at risk who may have no symptoms or signs of liver damage. Stratification in those with risk factors is potentially valuable. Our study population is of particular interest. Patterns of alcohol consumption in women are changing, with $16 \%$ of women in England consuming above recommended limits and this behaviour is highest in the 55-64 year old group [58]. Further work is required to demonstrate the generalisability of our findings, and to further investigate the predictive ability of ELF, to other community-based populations, but these data indicate that ELF may have a role in the stratification of risk years before the development of clinically apparent liver disease in asymptomatic individuals with common risk factors for chronic liver disease.

\section{Supplementary information}

Supplementary information accompanies this paper at https://doi.org/10. 1186/s12876-020-01251-w.

Additional file 1: Table S1. ICD-10 codes and / or death certificate text of first LREs for the cases. Table S2. Assay results for individual components of the ELF test and calculated ELF test score for cases and controls.

\section{Abbreviations}

ELF: Enhanced Liver Fibrosis (test); NASH: Non-alcoholic steatohepatitis; HA: Hyaluronic acid; TIMP-1: Tissue inhibitor of matrix metalloproteinase-1; PIIINP: Aminoterminal propeptide of procollagen type III; CLD: Chronic liver disease; NAFLD: Nonalcoholic fatty liver disease; BMI: Body mass index; LRE: Liver-related event; UKCTOCS: United Kingdom Trial of Ovarian Cancer Screening; HR: Hazard ratio; PRoBE: Prospective-specimen-collection, retrospective-blinded-evaluation; CA125: Cancer antigen 125; NRES: National Research Ethics Service; CMO: Chief Medical Officer; IMD: Index of Multiple Deprivation; ICD: International Classification of Diseases; HES: Hospital Episode Statistics; NICE: National Institute for Health and Care Excellence; (AU) ROC: (Area under the) receiver operator characteristic; LFT: Liver function tests; NHANES: National Health and Nutrition Examination Survey; AST: Aspartate aminotransferase; APRI: AST to platelet ratio; Fib-4: Fibrosis-4

\section{Acknowledgements}

We thank the volunteers for their samples / data and everyone involved in design, conduct and oversight of UKCTOCS.

WMR is a NIHR Senor investigator and WMR and UM receive support from the ULCH NIHR BRC.

\section{Authors' contributions}

All authors were involved in study design. PMT, SA, AGM, AR, UM and WMR were involved in data collection. PMT, UM and WMR drafted the manuscripts and figures. PMT, JP, ST, UM, WMR, SH and MB performed the statistical analysis. All authors critically revised the manuscript and approved the final version.

\section{Funding}

UKCTOCS, was funded by Medical Research Council (G9901012 and G0801228), Cancer Research UK (C1479/A2884), and the UK Department of Health, with additional support from The Eve Appeal.

For this nested study, there was no external funding.

UM and WMR are supported by the NIHR University College London Hospitals (UCLH) Biomedical Research Centre. WMR is a NIHR Senior Investigator. AGM, AR, MB and UM receive support from MRC core funding (MR_UU_12023). SA is part funded by Abcodia Pvt. Ltd.

The funding source or the sponsor had no role in the data collection, data analysis, data interpretation or writing of this work. The researchers are independent from the funders.

\section{Availability of data and materials}

The datasets used and/or analysed during this study may be available from the corresponding author on reasonable request.

\section{Ethics approval and consent to participate}

Written consent was obtained from participants in UKCTOCS for use of data and samples in future ethically approved secondary studies. UKCTOCS was approved by the UK North West Multicentre (Haydock) Research Ethics Committee (North West MREC 00/8/34). The current study, a secondary study nested in UKCTOCS, was approved by the National Research Ethics Service (NRES) Committee London - Bentham (Ref: 05/Q0505/57) on 10th August 2011.

\section{Consent for publication}

Not applicable.

\section{Competing interests}

UM has stocks awarded to her by UCL in Abcodia Pvt. Ltd. WMR is an inventor of the ELF test and has received fees from Siemens Healthineers for lecturing, travel, and consulting and research support. All the other authors declare no conflict of interest. 


\section{Author details}

'Division of Medicine, University College London, Institute for Liver and Digestive Health, Royal Free Hospital, Rowland Hill Street, London NW3 2PF, UK. ${ }^{2}$ MRC Clinical Trials Unit at UCL, Institute of Clinical Trials and Methodology, Faculty of Population Health Sciences, University College London, 2nd Floor, 90 High Holborn, London WC1V 6L, UK. ${ }^{3}$ Primary Care and Population Sciences Academic Unit, Faculty of Medicine, University of Southampton, Level C, South Academic Block, University Hospital

Southampton, Southampton SO16 6YD, UK.

\section{Received: 29 June 2019 Accepted: 30 March 2020}

Published online: 15 April 2020

\section{References}

1. Adult drinking habits in Great Britain: 2005 to 2016. Office for National Statistics 2017. Available at: https://www.ons.gov.uk/ peoplepopulationandcommunity/healthandsocialcare/ drugusealcoholandsmoking/bulletins/ opinionsandlifestylesurveyadultdrinkinghabitsingreatbritain/2005to2016. Accessed 4 Jan 2019.

2. Rao R, Roche A. Substance misuse in older people. BMJ. 2017;358:33885.

3. Rosenberg WMC, Voelker M, Thiel R, Becka M, Burt A, Schuppan D, Hubscher S, Roskams T, Pinzani M, Arthur MJP. Serum markers detect the presence of liver fibrosis: a cohort study. Gastroenterology. 2004;127(6): 1704-13.

4. Guha IN, Parkes J, Roderick P, Chattopadhyay D, Cross R, Harris S, Kaye P, Burt AD, Ryder SD, Aithal GP, et al. Noninvasive markers of fibrosis in nonalcoholic fatty liver disease: validating the European liver fibrosis panel and exploring simple markers. Hepatology. 2007;47(2):455-60.

5. Nobili V, Parkes J, Bottazzo G, Marcellini M, Cross R, Newman D, Vizzutti F, Pinzani M, Rosenberg WM. Performance of ELF serum markers in predicting fibrosis stage in pediatric non-alcoholic fatty liver disease. Gastroenterology. 2009;136(1):160-7.

6. Mayo MJ, Parkes J, Adams-Huet B, Combes B, Mills AS, Markin RS, Rubin R, Wheeler $\mathrm{D}$, Contos $\mathrm{M}$, West AB, et al. Prediction of clinical outcomes in primary biliary cirrhosis by serum enhanced liver fibrosis assay. Hepatology. 2008;48(5):1549-57.

7. Parkes J, Guha IN, Roderick P, Harris S, Cross R, Manos MM, Irving W, Zaitoun A, Wheatley M, Ryder S, et al. Enhanced liver fibrosis (ELF) test accurately identifies liver fibrosis in patients with chronic hepatitis C. J Viral Hepat. 2011;18(1):23-31.

8. Trembling PM, Lampertico P, Parkes J, Tanwar S, Vigano M, Facchetti F, Colombo M, Rosenberg WM. Performance of enhanced liver fibrosis test and comparison with transient elastography in the identification of liver fibrosis in patients with chronic hepatitis B infection. J Viral Hepat. 2014; 21(6):430-8.

9. Parkes J, Roderick P, Harris S, Day C, Mutimer D, Collier J, Lombard M, Alexander G, Ramage J, Dusheiko G, et al. Enhanced liver fibrosis test can predict clinical outcomes in patients with chronic liver disease. Gut. 2010; 59(9):1245-51.

10. Trembling PM, Apostolidou S, Gentry-Maharaj A, Parkes J, Ryan A, Tanwar S, Burnell M, Jacobs I, Menon U, Rosenberg WM. Risk of chronic liver disease in post-menopausal women due to body mass index, alcohol and their interaction: a prospective nested cohort study within the United Kingdom collaborative trial of ovarian cancer screening (UKCTOCS). BMC Public Health. 2017;17(1):603.

11. Pepe MS, Feng Z, Janes H, Bossuyt PM, Potter JD. Pivotal evaluation of the accuracy of a biomarker used for classification or prediction: standards for study design. J Natl Cancer Inst. 2008;100(20):1432-8.

12. Menon U, Gentry-Maharaj A, Hallett R, Ryan A, Burnell M, Sharma A, Lewis S, Davies S, Philpott S, Lopes A, et al. Sensitivity and specificity of multimodal and ultrasound screening for ovarian cancer, and stage distribution of detected cancers: results of the prevalence screen of the UK collaborative trial of ovarian cancer screening (UKCTOCS). Lancet Oncol. 2009;10(4):32740.

13. Menon U, Gentry-Maharaj A, Ryan A, Sharma A, Burnell M, Hallett R, Lewis S, Lopez A, Godfrey K, Oram D, et al. Recruitment to multicentre trials--lessons from UKCTOCS: descriptive study. BMJ. 2008;337:a2079.

14. Menon U, Ryan A, Kalsi J, Gentry-Maharaj A, Dawnay A, Habib M, Apostolidou S, Singh N, Benjamin E, Burnell M, et al. Risk algorithm using serial biomarker measurements doubles the number of screen-detected cancers compared with a single-threshold rule in the United Kingdom collaborative trial of ovarian cancer screening. J Clin Oncol. 2015;33(18): 2062-71.

15. Jacobs IJ, Parmar M, Skates SJ, Menon U. Ovarian cancer screening: UKCTOCS trial - Authors' reply. Lancet. 2016;387(10038):2603-4.

16. Drinkaware. Alcohol unit guidelines. London: Drinkaware. Available at: http://www.drinkaware.co.uk. Accessed 4 Jan 2019.

17. Indices of Deprivation 2007. The National Archives. Available at: https:// webarchive.nationalarchives.gov.uk/20100411141238/http:/www. communities.gov.uk/communities/neighbourhoodrenewal/deprivation/ deprivation07/. Accessed 14 Dec 2018.

18. Burnell M, Gentry-Maharaj A, Ryan A, Apostolidou S, Habib M, Kalsi J, Skates S, Parmar M, Seif MW, Amso NN, et al. Impact on mortality and cancer incidence rates of using random invitation from population registers for recruitment to trials. Trials. 2011;12:61.

19. Leon DA, McCambridge J. Liver cirrhosis mortality rates in Britain from 1950 to 2002: an analysis of routine data. Lancet. 2006;367(9504):52-6.

20. Liu B, Balkwill A, Reeves G, Beral V. Body mass index and risk of liver cirrhosis in middle aged UK women: prospective study. BMJ. 2010;340:c912.

21. Thiele M, Madsen BS, Hansen JF, Detlefsen S, Antonsen S, Krag A. Accuracy of the enhanced liver fibrosis test vs fibrotest, elastography and indirect markers in detection of advanced fibrosis in patients with alcoholic liver disease. Gastroenterology. 2018;154(5):1369-79.

22. Fisher LD, Lin DY. Time-dependent covariates in the cox proportionalhazards regression model. Annu Rev Public Health. 1999;20:145-57.

23. Suissa S. Immortal time bias in pharmaco-epidemiology. Am J Epidemiol. 2008;167(4):492-9.

24. van Walraven C, Davis D, Forster AJ, Wells GA. Time-dependent bias was common in survival analyses published in leading clinical journals. J Clin Epidemiol. 2004;57(7):672-82

25. Bedossa P, Poynard T. An algorithm for the grading of activity in chronic hepatitis C. The METAVIR Cooperative Study Group. Hepatology. 1996;24(2): 289-93.

26. Kennedy OJ, Parkes J, Tanwar S, Trembling PM, Rosenberg WM. The enhanced liver fibrosis (ELF) panel: analyte stability under common sample storage conditions used in clinical practice. J Appl Lab Med. 2017;1 (6):720-8.

27. Bolton-Smith C, Woodward M, Tunstall-Pedoe H, Morrison C. Accuracy of the estimated prevalence of obesity from self reported height and weight in an adult Scottish population. J Epidemiol Community Health. 2000;54(2): $143-8$.

28. Hill A, Roberts J. Body mass index: a comparison between self-reported and measured height and weight. J Public Health Med. 1998;20(2):206-10.

29. Nieto-Garcia FJ, Bush TL, Keyl PM. Body mass definitions of obesity: sensitivity and specificity using self-reported weight and height. Epidemiology. 1990;1(2):146-52.

30. Roberts RJ. Can self-reported data accurately describe the prevalence of overweight? Public Health. 1995;109(4):275-84.

31. Dahl AK, Hassing LB, Fransson El, Pedersen NL. Agreement between selfreported and measured height, weight and body mass index in old age--a longitudinal study with 20 years of follow-up. Age Ageing. 2010;39(4):445-51.

32. Stevens J, Keil JE, Waid LR, Gazes PC. Accuracy of current, 4-year, and 28year self-reported body weight in an elderly population. Am J Epidemiol. 1990;132(6):1156-63.

33. Dahl AK, Reynolds CA. Accuracy of recalled body weight--a study with 20years of follow-up. Obesity (Silver Spring). 2013;21(6):1293-8.

34. Perry GS, Byers TE, Mokdad AH, Serdula MK, Williamson DF. The validity of selfreports of past body weights by U.S. adults. Epidemiology. 1995;6(1):61-6.

35. Must A, Willett WC, Dietz WH. Remote recall of childhood height, weight, and body build by elderly subjects. Am J Epidemiol. 1993;138(1):56-64.

36. Ratib S, Fleming KM, Crooks CJ, Aithal GP, West J. 1 and 5 year survival estimates for people with cirrhosis of the liver in England, 1998-2009: a large population study. J Hepatol. 2014;60(2):282-9.

37. Fagan KJ, Pretorius CJ, Horsfall LU, Irvine KM, Wilgen U, Choi K, Fletcher LM, Tate J, Melino M, Nusrat S, et al. ELF score $>/=9.8$ indicates advanced hepatic fibrosis and is influenced by age, steatosis and histological activity. Liver Int. 2015;35(6):1673-81.

38. Williams R, Aspinall R, Bellis M, Camps-Walsh G, Cramp M, Dhawan A, Ferguson J, Forton D, Foster G, Gilmore I, et al. Addressing liver disease in the UK: a blueprint for attaining excellence in health care and reducing premature mortality from lifestyle issues of excess consumption of alcohol, obesity, and viral hepatitis. Lancet. 2014;384(9958):1953-97. 
39. Scaglione S, Kliethermes S, Cao G, Shoham D, Durazo R, Luke A, Volk ML. The epidemiology of cirrhosis in the United States: a population-based study. J Clin Gastroenterol. 2015;49(8):690-6.

40. Ratib S, West J, Crooks CJ, Fleming KM. Diagnosis of liver cirrhosis in England, a cohort study, 1998-2009: a comparison with cancer. Am J Gastroenterol. 2014;109(2):190-8.

41. McLernon DJ, Donnan PT, Ryder S, Roderick P, Sullivan FM, Rosenberg W, Dillon JF. Health outcomes following liver function testing in primary care: a retrospective cohort study. Fam Pract. 2009;26(4):251-9.

42. Johnston DE. Special considerations in interpreting liver function tests. Am Fam Physician. 1999;59(8):2223-30.

43. Harman DJ, Ryder SD, James MW, Jelpke M, Ottey DS, Wilkes EA, Card TR, Aithal GP, Guha IN. Direct targeting of risk factors significantly increases the detection of liver cirrhosis in primary care: a cross-sectional diagnostic study utilising transient elastography. BMJ Open. 2015:5(4):e007516.

44. Harris R, Harman DJ, Card TR, Aithal GP, Guha IN. Prevalence of clinically significant liver disease within the general population, as defined by noninvasive markers of liver fibrosis: a systematic review. Lancet Gastroenterol Hepatol. 2017;2(4):288-97.

45. Castera L, Foucher J, Bernard PH, Carvalho F, Allaix D, Merrouche W, Couzigou P, de Ledinghen V. Pitfalls of liver stiffness measurement: a 5-year prospective study of 13,369 examinations. Hepatology. 2010;51(3):828-35.

46. European Association for Study of L. Asociacion Latinoamericana Para el Estudio del H: EASL-ALEH clinical practice guidelines: non-invasive tests for evaluation of liver disease severity and prognosis. J Hepatol. 2015;63(1):237-64.

47. Fraquelli M, Rigamonti C, Casazza G, Conte D, Donato MF, Ronchi G, Colombo M. Reproducibility of transient elastography in the evaluation of liver fibrosis in patients with chronic liver disease. Gut. 2007;56(7):968-73.

48. National Institute for Health and Care Excellence (2016) Non-alcoholic fatty liver disease (NAFLD): assessment and management (NICE Guideline 49). Available at: https://www.nice.org.uk/guidance/ng49/resources.

49. Srivastava A, Gailer R, Tanwar S, Trembling P, Parkes J, Rodger A, Suri D, Thorburn D, Sennett K, Morgan S, et al. Prospective evaluation of a primary care referral pathway for patients with non-alcoholic fatty liver disease. J Hepatol. 2019;71(2):371-8.

50. Bazerbachi F, Haffar S, Wang Z, Cabezas J, Arias-Loste MT, Crespo J, DarwishMurad S, Ikram MA, Olynyk JK, Gan E, et al. Range of normal liver stiffness and factors associated with increased stiffness measurements in apparently healthy individuals. Clin Gastroenterol Hepatol. 2019;17(1):54-64 e51.

51. Kim D, Kim WR, Kim HJ, Therneau TM. Association between noninvasive fibrosis markers and mortality among adults with nonalcoholic fatty liver disease in the United States. Hepatology. 2013;57(4):1357-65.

52. Lopez IC, Aroca FG, Bernal MDF, Mompean JAL, Bernal AB, Martinez AMH, Barba EM, Velasco JAN, Paricio PP. Utility of the ELF test for detecting steatohepatitis in morbid obese patients with suspicion of nonalcoholic fatty liver disease. Obes Surg. 2017;27(9):2347-53.

53. de Vries EMG, Farkkila M, Milkiewicz P, Hov JR, Eksteen B, Thorburn D, Chazouilleres O, Pares A, Nygard S, Gilja OH, et al. Enhanced liver fibrosis test predicts transplant-free survival in primary sclerosing cholangitis, a multi-Centre study. Liver Int. 2017;37(10):1554-61.

54. Puigvehi M, Hernandez J, Broquetas T, Coll S, Garcia-Retortillo M, Canete N, Gimenez MD, Garcia M, Bory F, Salvado M, et al. Diagnostic accuracy of the enhanced liver fibrosis (ELF(R)) score using HCV-infected serum samples cryopreserved for up to 25 years. PLoS One. 2016;11(12):e0164883.

55. Loo WM, Goh GB, Wang Y, Yuan JM, Ong L, Dan YY, Koh WP. Enhanced liver fibrosis score as a predictor of hepatocellular carcinoma. Clin Chem. 2018;64(9):1404-5.

56. Yoo EJ, Kim BK, Kim SU, Park JY, Kim DY, Ahn SH, Han KH, Chon CY, Kim HS. Normal enhanced liver fibrosis (ELF) values in apparently healthy subjects undergoing a health check-up and in living liver donors in South Korea. Liver Int. 2013:33(5):706-13.

57. Lichtinghagen R, Pietsch D, Bantel H, Manns MP, Brand K, Bahr MJ. The enhanced liver fibrosis (ELF) score: normal values, influence factors and proposed cut-off values. J Hepatol. 2013;59(2):236-42.

58. Health and Social Care Information Centre. Health Survey for England 2015: Adult alcohol consumption. London: HSIC; 2016.

\section{Publisher's Note}

Springer Nature remains neutral with regard to jurisdictional claims in published maps and institutional affiliations.

\section{Ready to submit your research? Choose BMC and benefit from:}

- fast, convenient online submission

- thorough peer review by experienced researchers in your field

- rapid publication on acceptance

- support for research data, including large and complex data types

- gold Open Access which fosters wider collaboration and increased citations

- maximum visibility for your research: over $100 \mathrm{M}$ website views per year

At $\mathrm{BMC}$, research is always in progress.

Learn more biomedcentral.com/submissions 